Article

\title{
Quantification of Urinary Phenyl- $\gamma$-Valerolactones and Related Valeric Acids in Human Urine on Consumption of Apples
}

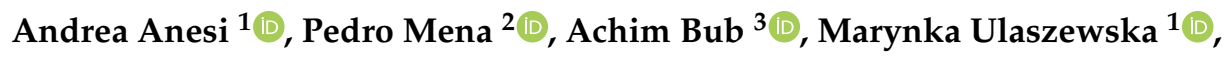 \\ Daniele Del Rio ${ }^{4,5}$, Sabine E. Kulling ${ }^{6}$ and Fulvio Mattivi ${ }^{1,7, *(D)}$ \\ 1 Department of Food Quality and Nutrition, Research and Innovation Centre, Fondazione Edmund \\ Mach (FEM), 38010 San Michele all'Adige, Italy; andrea.anesi@fmach.it (A.A.); \\ maria.ulaszewska@fmach.it (M.U.) \\ 2 Human Nutrition Unit, Department of Food \& Drug, University of Parma, 43121 Parma, Italy; \\ pedromiguel.menaparreno@unipr.it \\ 3 Department of Physiology and Biochemistry of Nutrition, Max Rubner-Institut, 76131 Karlsruhe, Germany; \\ achim.bub@mri.bund.de \\ 4 School of Advanced Studies on Food and Nutrition, and Microbiome Research Hub, University of Parma, \\ 43121 Parma, Italy; daniele.delrio@unipr.it \\ 5 Human Nutrition Unit, Department of Veterinary Medicine, University of Parma, 43121 Parma, Italy \\ 6 Department of Safety and Quality of Fruit and Vegetables, Max Rubner-Institut, 76131 Karlsruhe, Germany; \\ Sabine.Kulling@mri.bund.de \\ 7 Bioorganic Chemistry Laboratory, Department of Physics, University of Trento, 38123 Povo, Italy \\ * Correspondence: fulvio.mattivi@unitn.it; Tel.: +39-0461-615-259
}

Received: 13 September 2019; Accepted: 24 October 2019; Published: 29 October 2019

\begin{abstract}
Flavan-3-ols are dietary bioactive molecules that have beneficial effects on human health and reduce the risk of various diseases. Monomeric flavan-3-ols are rapidly absorbed in the small intestine and released in the blood stream as phase II conjugates. Polymeric flavan-3-ols are extensively metabolized by colonic gut microbiota into phenyl- $\gamma$-valerolactones and their related phenylvaleric acids. These molecules are the main circulating metabolites in humans after the ingestion of flavan-3-ol rich-products; nevertheless, they have received less attention and their role is not understood yet. Here, we describe the quantification of 8 phenyl- $\gamma$-valerolactones and 3 phenylvaleric acids in the urine of 11 subjects on consumption of apples by using UHPLC-ESI-Triple Quad-MS with pure reference compounds. Phenyl- $\gamma$-valerolactones, mainly as sulfate and glucuronic acid conjugates, reached maximum excretion between 6 and 12 after apple consumption, with a decline thereafter. Significant differences were detected in the cumulative excretion rates within subjects and in the ratio of dihydroxyphenyl- $\gamma$-valerolactone sulfate to glucuronide conjugates. This work observed for the first time the presence of two distinct metabotypes with regards to the excretion of phenyl- $\gamma$-valerolactone phase II conjugates.
\end{abstract}

Keywords: phenyl- $\gamma$-valerolactone; phenylvaleric acid; flavan-3ols; proanthocyanidins; apples; urine; LC-MS/MS; LC-MS; metabolic phenotype

\section{Introduction}

In the context of healthy lifestyles and disease prevention, flavan-3-ols are considered as dietary bioactive molecules, food constituents that are not essential for humans, but which may contribute in reducing the risk of various diseases and promoting healthy aging [1].

Flavan-3-ols are a class of phytochemicals widely found in nuts, fruits, and vegetables, mostly in almonds, apples, banana, berries, pears, grapes and red wine, cocoa, and legumes [2-8]. Flavan-3-ols 
are found as simple monomers, (+)-catechin, (-)-epicatechin, (-)-epigallocatechin and their galloyl derivatives, or assembled into oligomers and polymers that are collectively named proanthocyanidins (PACs) (Figure 1).<smiles>Oc1cc(O)c2c(c1)O[C@H](c1ccc(O)c(O)c1)[C@H](O)C2</smiles>

(-)-epicatechin<smiles>Oc1cc(O)c2c(c1)O[C@H](c1ccc(O)c(O)c1)[C@H](O)C2c1c(O)cc(O)c2c1O[C@H](c1ccc(O)c(O)c1)[C@H](O)C2</smiles>

Procyanidin $B_{2}$<smiles>[R2]c1ccc(CC([R6])CCC(=O)O)cc1[R1]</smiles>

dihydroxyphenyl-VA<smiles>[R3]c1ccc(C[C@@H]2CCC(=O)O2)cc1[R3]</smiles>

dihydroxyphenyl- $\gamma$-VL<smiles>Oc1cc(O)c2c(c1)O[C@H](c1cc(O)c(O)c(O)c1)[C@H](O)C2</smiles>

(-)-gallocatechin<smiles>Oc1cc(O)c2c(c1)O[C@H](c1cc(O)c(O)c(O)c1)[C@H](O)C2c1c(O)cc(O)c2c1O[C@H](c1cc(O)c(O)c(O)c1)[C@H](O)C2</smiles>

Prodelphinidin $\mathrm{B}_{2}$<smiles>[R]c1cc(C[C@@H]2CCC(=O)O2)cc([R3])c1[R]</smiles>

Figure 1. Left: structures of (-)-epicatechin, the dimer procyanidin $B_{2}$, a dihydroxyphenyl- $\gamma$ valerolactone (VL) and the related phenyl-valeric acid (VA). Right: structure of the (-)-gallocatechin, its dimeric form prodelphinidin $B_{2}$ and a trihydroxyphenyl-VL. Substituents $\left(R_{1}, R_{2}, R_{3}\right)$ can be hydroxyl groups, sulfate, methoxy, or glucuronic acid, while $\mathrm{R}_{4}$ can be hydrogen (yielding 5-(3', 4'-dihydroxyphenyl)VA) or hydroxyl group (yielding 4-hydroxy-5-(3',4'-dihydroxyphenyl)VA).

Flavan-3-ols from cocoa have been extensively studied for their benefits on human health [7,9-13]. The consumption of cocoa flavan-3-ols proved to have cardioprotective effects in healthy individuals; improvement of endothelial function and flow-mediated dilation (FMD), decrease in blood pressure, increase in HDL, and decrease in LDL and lipid oxidation are among the most beneficial effects observed after regular consumption of cocoa. Positive effects were also demonstrated on the functionalities of the central nervous system, gastro-intestinal tract, and immune system [14].

In 2012, the Europe Community Regulation 1924/2006 authorized a health claim related to the assumption of cocoa flavan-3-ols to maintain good blood vessel elasticity: the daily consumption of $200 \mathrm{mg}$ of cocoa flavan-3-ols is considered sufficient to obtain a beneficial effect [15].

The consumption of apples has proved to have similar positive effects on vascular function and has been positively correlated to a lower risk of lung cancer, abdominal aortic calcification, coronary heart disease, and type II diabetes [16-18]. The cardioprotective effects of apples have been attributed to the high content of flavan-3-ols, which improve endothelial function by enhancing nitric oxide (NO) bioavailability [18,19].

Apples are widely consumed worldwide and are a good source of flavan-3-ols $[2,16,17,20,21]$. Flavan-3-ols represent the major class of apple polyphenols, ranging between $71 \%$ and $90 \%$ of total polyphenols, depending on the cultivar [20]. The major constituents are oligomeric PAC (ranging from $38.8 \mathrm{mg}$ to $162.2 \mathrm{mg} / 100 \mathrm{~g}$ of fresh weight, FW), procyanidin B2 (5.6-19.3 mg/100 $\mathrm{g}$ FW), and 
(-)-epicatechin (5.2-18.4 mg/100 g FW), while (+)-catechin $(0.5-3.40 \mathrm{mg} / 100 \mathrm{~g} \mathrm{FW})$ is present in lower amounts. Hydroxycinnamic acids (mainly $5^{\prime}$-caffeoylquinic acid and p-coumaroylquinic acid) represent between $4 \%$ and $18 \%$ of total polyphenols, flavonols (mainly quercetin glycosides) between $1 \%$ and $11 \%$, dihydrochalcones (phloridzin and phloretin-xyloglucoside) between $2 \%$ and $6 \%$, and anthocyanins (cyanidin glycosides in red apple varieties; $1-3 \%$ ) are the other important constituents of apple polyphenols [20]. A remarkable diversity in the absolute content and pattern of the different polyphenols among apple species and cultivars has been evidenced, which is, in part, the result of the domestication process [21].

Monomeric flavan-3-ols are absorbed in the small intestine. Phase II enzymes transform them mainly into glucuronide-conjugates that can enter the systemic circulation, reaching a maximum plasma concentration within $2-4 \mathrm{~h}$ of food consumption [8,22-24]. In the liver, simple flavan-3-ols are converted to sulfate and methyl derivatives [4,25]. Dimeric and trimeric forms can also be absorbed, but to a lower extent and their bioavailability is up to 100 -fold lower $[24,26]$.

Oligomeric PAC with a degree of polymerization greater than $n=3$ are not degraded in the stomach under acidic conditions and their polymeric nature limits the absorption in the small intestine. Therefore, their contribution to the pool of circulating monomeric flavan-3-ols in human plasma is neglectable $[3,5,13,24,27]$. It is estimated that over $70 \%$ of ingested flavan-3-ols passes un-metabolized through the upper part of intestine and reaches the colon, where PAC are extensively metabolized by local gut microbiota into phenyl $-\gamma$-valerolactones (PVLs) and their related phenylvaleric acids (PVAs) (Figure 1) $[8,22,23,28]$. PVLs have been proposed as (potential) biomarkers of flavan-3-ol intake $[8,26]$. Microbial flavan-3-ol catabolism is characterized by flavan-3-ol subunit cleavage (in the case of PACs), C-ring opening, lactonization, decarboxylation, dehydroxylation, and $\beta$-oxidation [3,5,25,29-32]. Phenylpropionic acids, phenylacetic acids, and benzoic acids are considered as end point catabolites of the microbial degradation of the flavonoid family.

Microbial metabolites can be absorbed from the gut/colon and are then subjected to modifications in the liver by endogenous phase II enzymes; glucuronide-, sulfate- and methyl-conjugates enter the systemic circulation and are finally excreted in the urine, while non-conjugated metabolites are eliminated in the faeces $[13,29,30,33]$.

Most of the data available on PVLs and PVAs is based on semi-quantitative, untargeted mass spectrometry (MS) $[4,32,33]$, or targeted approaches lacking pure standards for accurate quantification [5,6,24]. With this approach, the annotation process is usually at level 2 or 3 of the Metabolomics Standards Initiative (MSI), i.e., with compounds putatively annotated (level 2) or putatively assigned to classes (level 3) and is lacking an accurate quantitation against a pure standard. Advances in asymmetric synthesis have led to the availability of pure PVL aglycones, glucuronidated, and sulfated conjugates, opening the way for robust quantitative and targeted-MS approaches [31,34] that can provide precious information on the bioavailability and nutrikinetics of flavan-3-ols in humans.

In this work, we report on the quantification of 8 PVLs and 3 PVAs in the urine of 11 subjects up to $48 \mathrm{~h}$ after apple consumption, using an UHPLC-ESI-Triple Quad-MS, together with the analysis of the phase II metabolites of epicatechin based on an untargeted approach. To the best of our knowledge, this is the first time that the accurate quantification of PVLs derived from apple flavan-3-ols is carried out.

\section{Results}

\subsection{Flavan-3-ol and PAC Composition of Study Apples}

Study participants ingested, on average, $688.85 \mu \mathrm{mol}$ of (-)-epicatechin, $176.35 \mu \mathrm{mol}$ of procyanidin $\mathrm{B} 1,1882.18 \mu \mathrm{mol}$ of procyanidin B2, and $2922.50 \mu \mathrm{mol}$ of PACs, with a mean degree of polymerization $(\mathrm{mDP})$ of 8.5 (Table 1). The complete composition of Elstar apples used for the intervention is available in Table S1. The two control treatments (placebo) lacked flavan-3-ols. 
Table 1. Estimated content of monomeric flavan-3-ols and dimeric and oligomeric PAC in the apple var. $\operatorname{Elstar}(n=3)$.

\begin{tabular}{cc}
\hline Flavan-3-ol & Content $(\boldsymbol{\mu m o l})$ \\
\hline Free $(+)$-catechin & $86.57 \pm 4.68$ \\
\hline Free $(-)$-epicatechin & $688.85 \pm 29.96$ \\
\hline Free gallocatechin & $0.17 \pm 0.03$ \\
\hline Free epigallocatechin & $0.00 \pm 0.00$ \\
\hline Free catechin gallate & $0.18 \pm 0.00$ \\
\hline Procyanidin B1 & $176.35 \pm 11.90$ \\
\hline Procyanidin B2 & $1882.18 \pm 62.13$ \\
\hline Total PACs & $2922.50 \pm 121.74$ \\
\hline PAC mDP & $8.5 \pm 0.01$ \\
\hline Total flavan-3-ols & 5756.81 \\
\hline
\end{tabular}

\subsection{Targeted Analysis of Free and Conjugated PVLs and PVAs in Urine}

The targeted metabolomics analysis of the urine collected revealed the presence of signals of 8 conjugated PVLs and 3 PVAs (Table 2). Free PVLs and PVAs were not detected. PVLs and PVAs were not detectable in urine samples from the control intervention (same diet exception of the apple intake).

Table 2. Conjugated PVL and PVA detected in the urine of 11 study participants with the transition used for their quantitation and their retention times. VL: valerolactone; VA: valeric acid.

\begin{tabular}{|c|c|c|c|}
\hline Metabolite & ID & Transition $(m / z)$ & Retention Time (min) \\
\hline 5-phenyl- $\gamma$-VL-3'-sulfate & 1 & $271>191$ & 2.88 \\
\hline 5-(3'-hydroxyphenyl)- $\gamma$-VL-4'-sulfate & 2 & $287>207$ & 2.66 \\
\hline 5-phenyl- $\gamma$-VL-3'-glucuronide & 3 & $367>191$ & 2.10 \\
\hline 5-(hydroxyphenyl)- $\gamma$-VL-glucuronide $\left(3^{\prime}, 4^{\prime}\right.$ isomer) & 4 & $383>207$ & 1.76 \\
\hline 5-phenyl- $\gamma$-VL-methoxy-sulfate 1 & 5 & $301>206$ & 2.65 \\
\hline 5-phenyl- $\gamma$-VL-methoxy-sulfate 2 & 6 & $301>206$ & 2.83 \\
\hline 5-phenyl- $\gamma$-VL-sulfate-glucuronide & 7 & $463>207$ & 2.05 \\
\hline 5-(phenyl)- $\gamma$-VL-methoxy-glucuronide & 8 & $397>221$ & 2.03 \\
\hline 4-hydroxy-5-(hydroxyphenyl)-VA-sulfate & 9 & $305>225$ & 2.16 \\
\hline 4-hydroxy-5-(hydroxyphenyl)-VA-glucuronide & 10 & $401>225$ & 2.05 \\
\hline 4-hydroxy-5-phenyl-VA-methoxy-sulfate & 11 & $319>239$ & 2.12 \\
\hline
\end{tabular}

Four of the screened analytes were unambiguously assigned to specific PVLs, according to the retention time of pure standards and mass spectra, and quantified with external calibration. Since external standards were not available for all the tested metabolites (e.g., methoxy-sulfate and methoxy-glucuronide and PVA), we opted to use chemically related molecules (see Table S2 for details).

In [32], 15 conjugated PVLs and 8 PVAs were found to be markers of apple juice intake, predominantly sulfate-, glucuronide-, and methoxy conjugates of dihydroxy-PVL and -PVA, or a combination thereof (i.e., methoxy-sulfate and methoxy-glucuronide conjugates). Taking into account the flavan-3-ol profile of the apple powder, the dihydroxy PVLs and PVAs identified could be mainly derivatives of 5-( $3^{\prime}, 4^{\prime}$-dihydroxyphenyl)- $\gamma$-VL and 4-hydroxy-5-( $3^{\prime}, 4^{\prime}$-dihydroxyphenyl)-VA, respectively [8].

The presence of glucuronide- and sulfate-conjugates of PVLs and PVAs have been confirmed in other studies after consumption of almond [6], cocoa [5,23], cranberry [8,35,36], grape [37], and green tea $[28,29,38-40]$. 


\subsection{Bioavailability and Quantitative Determination of Conjugated PVL and PVA}

Accurate determination of flavan-3-ol breakdown products is of great importance in order to study their metabolic fate. In the vision of a personalized nutrition, it is important to study the inter-individual differences and calculate the minimum amount necessary to obtain a health effect.

Taking into account the most abundant metabolites (1, 2 and 4, which represent over $76.5 \%$ of the total excreted metabolites, all subjects but S6 exhibited maximum excretion between $6 \mathrm{~h}$ and $12 \mathrm{~h}$, with a decline thereafter (Figure 2). Subject 6 reached maximum excretion between $12 \mathrm{~h}$ and $24 \mathrm{~h}$. Subject 4 is the only one exhibiting notable excretion between $2 \mathrm{~h}$ and $4 \mathrm{~h}$. Less abundant metabolites are not excreted by all participants. Quantitative data at each time interval are available in Table S3.
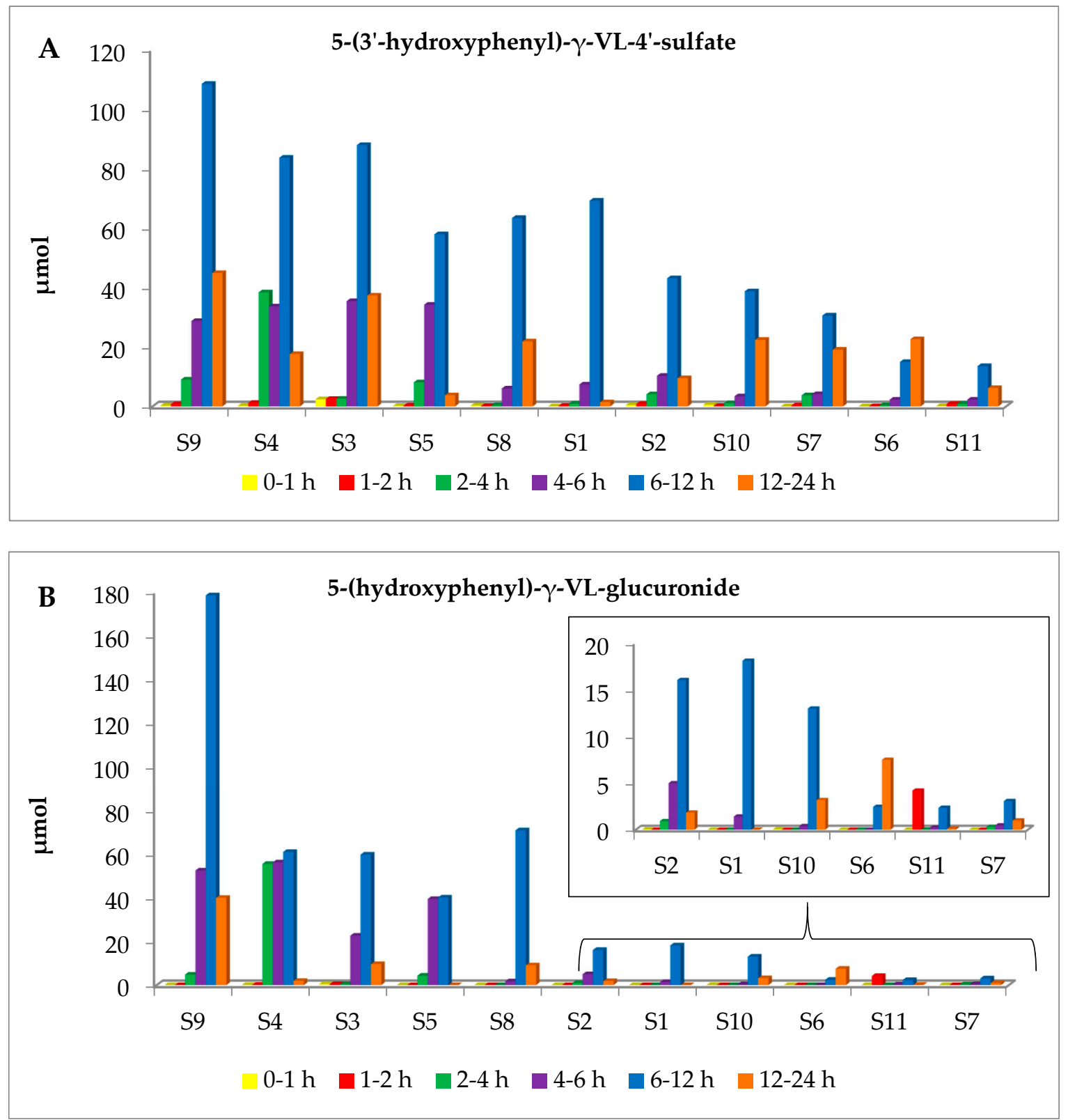

Figure 2. Urinary excretion of 5-(3'-hydroxyphenyl)- $\gamma$-VL-4'-sulfate (2) (A) and 5-(hydroxyphenyl)$\gamma$-VL-glucuronide (4) (B) in the 11 study subjects (S1-S11) at different time intervals. $0-1$ h: yellow bars; 1-2 h: red bars; 2-4 h: green bars; $4-6$ h: purple bars; 6-12 h: blue bars; $12-24$ h: orange bars. Subjects are shown in decreasing order of cumulative excretion in urine (AUC). Data were normalized according to urine volume. 
In the work of [32], PVLs did not reach their maximum plasma concentration in the first $5 \mathrm{~h}$ after apple juice consumption and the maximum concentration in urine was reached in the first $8-24 \mathrm{~h}$. These deviations compared to the results presented here might be due to differences in the amount and type of flavan-3-ol intake. In human intervention studies on green tea, PVLs appeared in the bloodstream between $5 \mathrm{~h}$ and $12 \mathrm{~h}$ after green tea consumption, while renal extraction occurred between $7.5 \mathrm{~h}$ and $24 \mathrm{~h}[38,40,41]$. Similarly, PVLs were detected in plasma within $6 \mathrm{~h}$ from cocoa intake and excreted in large amounts in urine up to $24 \mathrm{~h} \mathrm{[5].}$

From a quantitative point of view, there is a continuum in the cumulative excretion of conjugated PVLs and PVAs from high to low metabolizers (Figure 2). Apple intake resulted in cumulative excretion ranging from a minimum value of $70.68 \mu \mathrm{mol}$ (S6) to a maximum of $524.35 \mu \mathrm{mol}$ (S9); it is clear that significant differences, up to 7.5 times, exist within the subjects (Table 3 ).

Table 3. Urine cumulative excretion of phenyl- $\gamma$-valerolactones and phenylvaleric acids ( $\mu \mathrm{mol})$ in the interval T1-T24 in 11 subjects (S1-11). The values reported in brackets indicate the percentage of each metabolite on the sum of all detected compounds. ACE: average cumulative excretion ( \pm standard deviation).

\begin{tabular}{|c|c|c|c|c|c|c|c|c|c|c|c|c|}
\hline \multirow{2}{*}{$\begin{array}{l}\text { PVL and PVA } \\
\text { Metabolites }\end{array}$} & \multicolumn{12}{|c|}{ Cumulative Excretion ( $\mu \mathrm{mol})$ and Relative \% of Different Metabolites in the 11 Study Subjects } \\
\hline & S9 & S4 & S3 & S5 & S8 & S2 & S1 & $\mathrm{S} 10$ & S6 & S11 & S7 & ACE \\
\hline $\begin{array}{c}\text { 5-phenyl- } \\
\gamma \text {-VL-3'-sulfate }\end{array}$ & $\begin{array}{l}8.61 \\
(1.6)\end{array}$ & $\begin{array}{l}10.85 \\
(2.7)\end{array}$ & $\begin{array}{l}2.43 \\
0.8)\end{array}$ & $\begin{array}{l}2.95 \\
(1.4)\end{array}$ & $\begin{array}{l}0.56 \\
(0.3)\end{array}$ & $\begin{array}{l}8.33 \\
(7.7)\end{array}$ & $\begin{array}{l}2.17 \\
(1.9)\end{array}$ & $\begin{array}{l}24.09 \\
(20.9)\end{array}$ & $\begin{array}{l}7.02 \\
(9.9)\end{array}$ & $\begin{array}{l}53.23 \\
(43.3)\end{array}$ & $\begin{array}{l}3.31 \\
(4.5)\end{array}$ & $\begin{array}{c}11.23 \\
( \pm 15.38)\end{array}$ \\
\hline $\begin{array}{c}\text { 5-(3'-hydroxyphenyl)- } \\
\gamma \text {-VL-4'-sulfate }\end{array}$ & $\begin{array}{c}192.05 \\
(36.6)\end{array}$ & $\begin{array}{l}174.55 \\
(42.9)\end{array}$ & $\begin{array}{c}168.04 \\
(58.1)\end{array}$ & $\begin{array}{l}104.29 \\
(50.6)\end{array}$ & $\begin{array}{l}91.97 \\
(47.6)\end{array}$ & $\begin{array}{l}68.18 \\
(62.7)\end{array}$ & $\begin{array}{l}79.06 \\
(70.1)\end{array}$ & $\begin{array}{c}66.24 \\
(57.58)\end{array}$ & $\begin{array}{l}40.21 \\
(56.9)\end{array}$ & $\begin{array}{l}31.41 \\
(25.6)\end{array}$ & $\begin{array}{l}57.79 \\
(77.8)\end{array}$ & $\begin{array}{c}96.92 \\
( \pm 56.92)\end{array}$ \\
\hline $\begin{array}{c}\text { 5-phenyl- } \\
\gamma \text {-VL-3'-glucuronide }\end{array}$ & $\begin{array}{l}6.27 \\
(1.2)\end{array}$ & $\begin{array}{l}4.26 \\
(1.0)\end{array}$ & $\begin{array}{l}0.03 \\
(0.0)\end{array}$ & $\begin{array}{l}0.42 \\
(0.2)\end{array}$ & $\begin{array}{l}0.04 \\
(0.0)\end{array}$ & $\begin{array}{l}0.04 \\
(0.0)\end{array}$ & $\begin{array}{l}0.05 \\
(0.0)\end{array}$ & $\begin{array}{l}2.76 \\
(2.4)\end{array}$ & $\begin{array}{l}3.70 \\
(5.2)\end{array}$ & $\begin{array}{l}25.60 \\
(20.8)\end{array}$ & $\begin{array}{l}0.04 \\
(0.1)\end{array}$ & $\begin{array}{c}3.93 \\
( \pm 7.51)\end{array}$ \\
\hline $\begin{array}{l}\text { 5-(hydroxyphenyl)- } \\
\gamma \text {-VL-glucuronide }\end{array}$ & $\begin{array}{c}275.60 \\
(52.6)\end{array}$ & $\begin{array}{l}174.40 \\
(42.9)\end{array}$ & $\begin{array}{l}93.17 \\
(32.2)\end{array}$ & $\begin{array}{l}83.63 \\
(40.6)\end{array}$ & $\begin{array}{l}81.44 \\
(42.2)\end{array}$ & $\begin{array}{l}23.81 \\
(21.9)\end{array}$ & $\begin{array}{l}19.54 \\
(17.3)\end{array}$ & $\begin{array}{l}16.61 \\
(14.4)\end{array}$ & $\begin{array}{c}9.93 \\
(14.1)\end{array}$ & $\begin{array}{l}6.91 \\
(5.6) \\
\end{array}$ & $\begin{array}{l}4.82 \\
(6.5)\end{array}$ & $\begin{array}{c}71.81 \\
( \pm 85.64)\end{array}$ \\
\hline $\begin{array}{c}\text { 5-phenyl- } \\
\gamma \text {-VL-methoxy-sulfate } \\
\text { (1) }\end{array}$ & $\begin{array}{l}0.44 \\
(0.1)\end{array}$ & $\begin{array}{l}0.52 \\
(0.1)\end{array}$ & $\begin{array}{l}0.46 \\
(0.2)\end{array}$ & $\begin{array}{l}0.39 \\
(0.2)\end{array}$ & $\begin{array}{l}0.36 \\
(0.2)\end{array}$ & $\begin{array}{l}0.34 \\
(0.3)\end{array}$ & $\begin{array}{l}0.31 \\
(0.3)\end{array}$ & $\begin{array}{l}0.34 \\
(0.3)\end{array}$ & $\begin{array}{l}0.23 \\
(0.3)\end{array}$ & $\begin{array}{l}0.39 \\
(0.3)\end{array}$ & $\begin{array}{l}0.29 \\
(0.4)\end{array}$ & $\begin{array}{c}0.37 \\
( \pm 0.08)\end{array}$ \\
\hline $\begin{array}{c}\text { 5-phenyl- } \gamma \text {-VL-sulfate- } \\
\text { glucuronide }\end{array}$ & $\begin{array}{l}30.91 \\
(5.9) \\
\end{array}$ & $\begin{array}{c}33.92 \\
(8.3) \\
\end{array}$ & $\begin{array}{l}12.30 \\
(4.3) \\
\end{array}$ & $\begin{array}{l}10.67 \\
(5.2) \\
\end{array}$ & $\begin{array}{l}9.57 \\
(5.0)\end{array}$ & $\begin{array}{l}6.83 \\
(6.3) \\
\end{array}$ & $\begin{array}{l}5.51 \\
(4.9) \\
\end{array}$ & $\begin{array}{l}3.10 \\
(2.7) \\
\end{array}$ & $\begin{array}{l}6.87 \\
(9.7) \\
\end{array}$ & $\begin{array}{l}3.20 \\
(2.6) \\
\end{array}$ & $\begin{array}{l}5.49 \\
(7.4) \\
\end{array}$ & $\begin{array}{c}11.67 \\
( \pm 10.67)\end{array}$ \\
\hline $\begin{array}{l}\text { 4-hydroxy- } \\
\text { 5-(hydroxyphenyl)- } \\
\text { VA-sulfate }\end{array}$ & $\begin{array}{l}7.18 \\
(1.4)\end{array}$ & $\begin{array}{l}6.14 \\
(1.5)\end{array}$ & $\begin{array}{l}10.60 \\
(3.7)\end{array}$ & $\begin{array}{l}2.07 \\
(1.0)\end{array}$ & $\begin{array}{l}7.39 \\
(3.8)\end{array}$ & $\begin{array}{c}<\mathrm{LOD} \\
(0.0)\end{array}$ & $\begin{array}{l}4.67 \\
(4.1)\end{array}$ & $\begin{array}{l}0.06 \\
(0.1)\end{array}$ & $\begin{array}{l}1.85 \\
(2.6)\end{array}$ & $\begin{array}{l}0.30 \\
(0.2)\end{array}$ & $\begin{array}{l}1.82 \\
(2.4)\end{array}$ & $\begin{array}{c}3.82 \\
( \pm 3.58)\end{array}$ \\
\hline $\begin{array}{c}\text { 4-hydroxy- } \\
\text { 5-(hydroxyphenyl)- } \\
\text { VA-methoxy- sulfate }\end{array}$ & $\begin{array}{l}0.02 \\
(0.0)\end{array}$ & $\begin{array}{l}0.01 \\
(0.0)\end{array}$ & $\begin{array}{l}0.04 \\
(0.0)\end{array}$ & $\begin{array}{l}0.01 \\
(0.0)\end{array}$ & $\begin{array}{l}0.02 \\
(0.0)\end{array}$ & $\begin{array}{c}<\mathrm{LOD} \\
(0.0)\end{array}$ & $\begin{array}{c}<\mathrm{LOD} \\
(0.0)\end{array}$ & $\begin{array}{c}<\mathrm{LOD} \\
(0.0)\end{array}$ & $\begin{array}{l}0.02 \\
(0.0)\end{array}$ & $\begin{array}{l}0.01 \\
(0.0)\end{array}$ & $\begin{array}{l}0.01 \\
(0.0)\end{array}$ & $\begin{array}{c}0.01 \\
( \pm 0.01)\end{array}$ \\
\hline $\begin{array}{c}\text { 4-hydroxy- } \\
\text { 5-(hydroxyphenyl)- } \\
\text { VA-glucuronide }\end{array}$ & $\begin{array}{l}0.02 \\
(0.0)\end{array}$ & $\begin{array}{l}0.17 \\
(0.0)\end{array}$ & $\begin{array}{l}0.21 \\
(0.1)\end{array}$ & $\begin{array}{l}0.02 \\
(0.0)\end{array}$ & $\begin{array}{l}0.04 \\
(0.0)\end{array}$ & $\begin{array}{l}0.02 \\
(0.0)\end{array}$ & $\begin{array}{l}0.03 \\
(0.0)\end{array}$ & $\begin{array}{l}0.02 \\
(0.0)\end{array}$ & $\begin{array}{l}0.21 \\
(0.3)\end{array}$ & $\begin{array}{l}0.98 \\
(0.8)\end{array}$ & $\begin{array}{l}0.02 \\
(0.0)\end{array}$ & $\begin{array}{c}0.16 \\
( \pm 0.28)\end{array}$ \\
\hline $\begin{array}{c}\% \text { excretion (to total } \\
\text { PACs) }\end{array}$ & 17.9 & 13.9 & 9.9 & 7.0 & 6.6 & 3.7 & 3.9 & 3.9 & 2.4 & 4.2 & 2.5 & $\begin{array}{c}6.90 \\
( \pm 5.04)\end{array}$ \\
\hline
\end{tabular}

Among the screened metabolites, 2 and 4 presented the largest increments in urine (cumulative excretion range 31.41-192.05 $\mu \mathrm{mol}$ and 4.82-275.60 $\mu \mathrm{mol}$, respectively). Sulfate-conjugates of PVLs and PVAs were very abundant in this study, also in comparison to [32]. However, the use of appropriate reference compounds for the quantification in this work may provide more accurate quantitative data, overcoming one of the main limitations in the field of PVLs [31]. The percentage of excretion is also 
variable between subjects. Taking into account only the excretion relative to total PACs, this value ranges from $2.4 \%$ (S6) to $17.9 \%$ (S4).

2.4. The Ratio of Sulfate/Glucuronide Conjugates of 5- $\left(3^{\prime}, 4^{\prime}\right.$-dihydroxyphenyl)- $\gamma$-VL Suggests the Presence of Phase II Metabotypes

Metabolites 2 and 4 represent the most abundant metabolites excreted in urine in all subjects, ranging from 71.0 (S6) to 91.2\% (S5) of total metabolites, based on Area Under the Curve (AUC), except for S11. Methoxy-conjugates, sulfate-glucuronides, and PVAs were not considered in this calculation, as they represented a negligible proportion of the overall metabolites.

The cluster analysis, based on all quantified metabolites, revealed the existence of two groups (S1, S2, S3, S6, S10, S7 and S4, S5, S8, S9), while S11 is singled out from all the other subjects (Figure 3). These differences are explicable, taking into consideration the ratio of AUC of metabolite 2 to AUC of metabolite 4, and are not dependent on subject metadata (age, gender, and BMI).

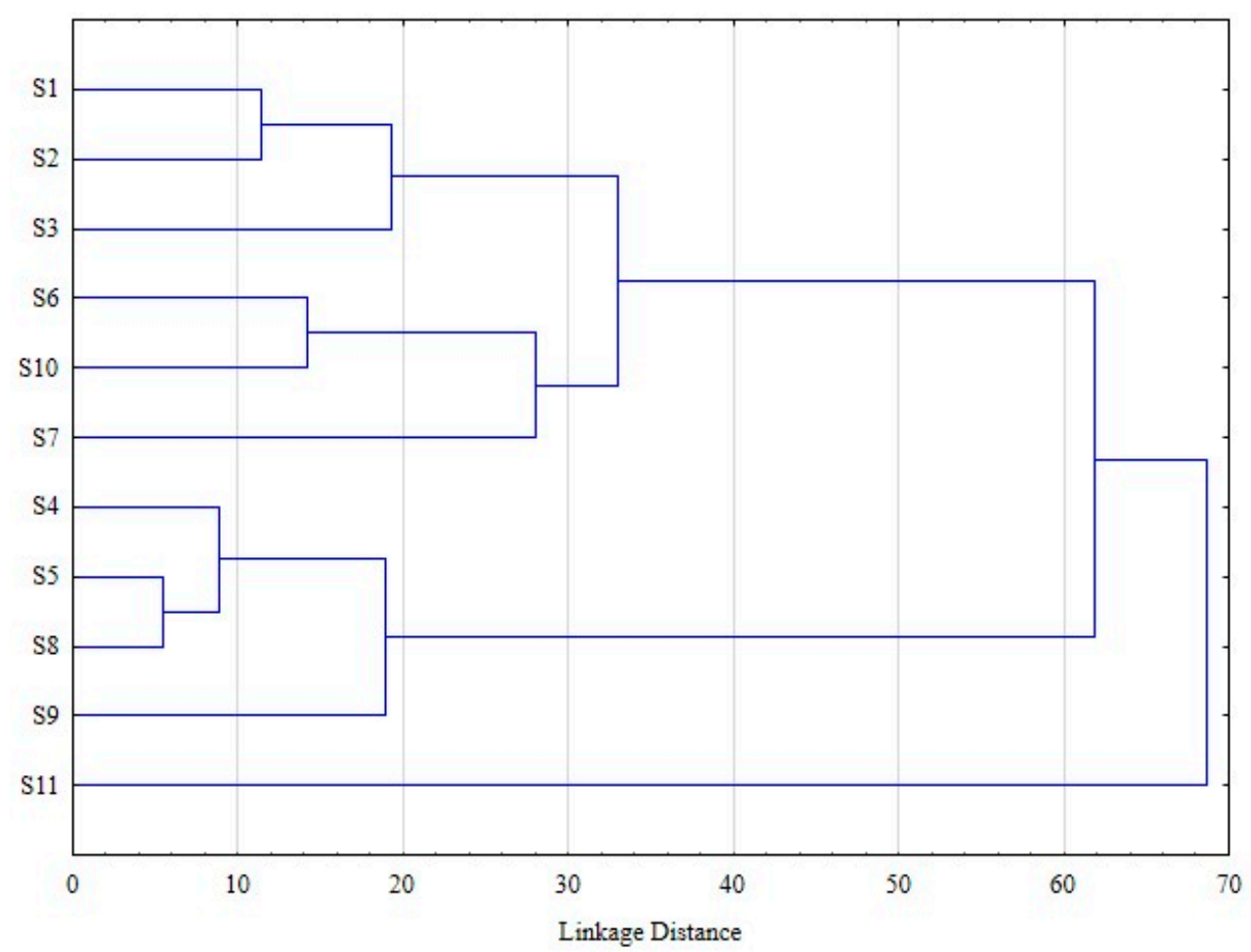

Figure 3. Cluster analysis based on percentages of excreted PVL and PVA metabolites in the 11 subjects (complete linkage, Euclidean distance).

The first subpopulation (S1, S2, S3, S6, S10 and S7) displayed a ratio in favour of sulfate conjugates (>1.8), while the second one has a ratio of approximately 1 (Table 4). S11, despite having a ratio in favour of sulfate conjugates, has higher proportions of monohydroxyPVL (64.2\%) compared to dihydroxyPVL (31.2\%).

Subjects displaying a ratio in favour of sulfate-conjugates excreted lower amount of metabolites, except for S3. It is known that, for some individuals, the excretion is dependent on the substrates and can reach up to $50 \%$ of the ingested polyphenols [25]. Nevertheless, these differences, related to the existence of putative metabotypes on the phase II conjugation of dihydroxyPVLs, require further research by using a large number of subjects and 5-( $3^{\prime}$-hydroxyphenyl)- $\gamma-\mathrm{VL}-4^{\prime}$-glucuronide or 5-(4'-hydroxyphenyl)- $\gamma$-VL-3'-glucuronide as standard for the quantification of metabolite 4 , since here it was quantified as $5-\left(5^{\prime}\right.$-hydroxyphenyl)- $\gamma$-VL-3'-glucuronide; the results might slightly change. 
Table 4. Ratio AUC (dihydroxy-PVL-sulfate/glucuronide), total AUC, and ratio epicatechin sulfate/glucuronide in the 11 study participants.

\begin{tabular}{cccc}
\hline Subject & $\begin{array}{c}\text { Ratio 5-Hydroxyphenyl- } \boldsymbol{\gamma} \text {-VL } \\
\text { Sulfate/Glucuronide }\end{array}$ & $\begin{array}{c}\text { Cumulative Excretion } \\
(\mu \mathrm{mol})\end{array}$ & $\begin{array}{c}\text { Ratio Epicatechin } \\
\text { Sulfate/Glucuronide }\end{array}$ \\
\hline S1 & 4.0 & 112.73 & 3.7 \\
\hline S2 & 2.9 & 108.77 & 7.2 \\
\hline S3 & 1.8 & 289.18 & 6.8 \\
\hline S4 & 1.0 & 406.98 & 5.8 \\
\hline S5 & 1.2 & 206.10 & 6.7 \\
\hline S6 & 4.0 & 70.68 & 3.9 \\
\hline S7 & 12.0 & 74.30 & 8.9 \\
\hline S8 & 1.1 & 193.03 & 2.5 \\
\hline S9 & 0.7 & 524.35 & 2.3 \\
\hline S10 & 4.0 & 115.13 & 3.6 \\
\hline S11 & 4.5 & 122.79 & 4.8 \\
\hline
\end{tabular}

\subsection{Untargeted Analysis of Conjugated (-)-Epicatechin}

The untargeted metabolomics approach revealed the presence of the sulfate, methoxy-sulfate, glucuronide, and methoxy-glucuronide conjugates of (-)-epicatechin in urine. The exact quantitation of epicatechin phase II metabolites was beyond the scope of this work, due to (a) the lack of commercially available standards for epicatechin phase II metabolites and (b) to avoid problems of misquantification derived from the quantification of epicatechin phase II metabolites according to (-)-epicatechin standard. However, as precursors of valerolactone and valeric acid derivatives, we reported their peak areas (see Table S4). As shown in Figure 4, epicatechin phase II metabolites are excreted in urine starting from $1 \mathrm{~h}$ to $6 \mathrm{~h}$ after apple consumption. The quantitative differences among the subjects in the urinary excretion of epicatechin conjugates were lower than those observed for PVLs and PVAs. In fact, excluding the high metabolizer S3, all the other subjects displayed similar cumulative excretion of epicatechin conjugates, with a fold change of 2.9 existing between S6 and S2 (data not shown). The cluster analysis based on epicatechin phase II metabolites was different than that obtained for PVL (Figure S1), suggesting that important differences exist between human and gut microbial metabolisms. The ratios epicatechin sulfate to glucuronic acid conjugates were also different from those obtained for PVL metabolites (Table 4).

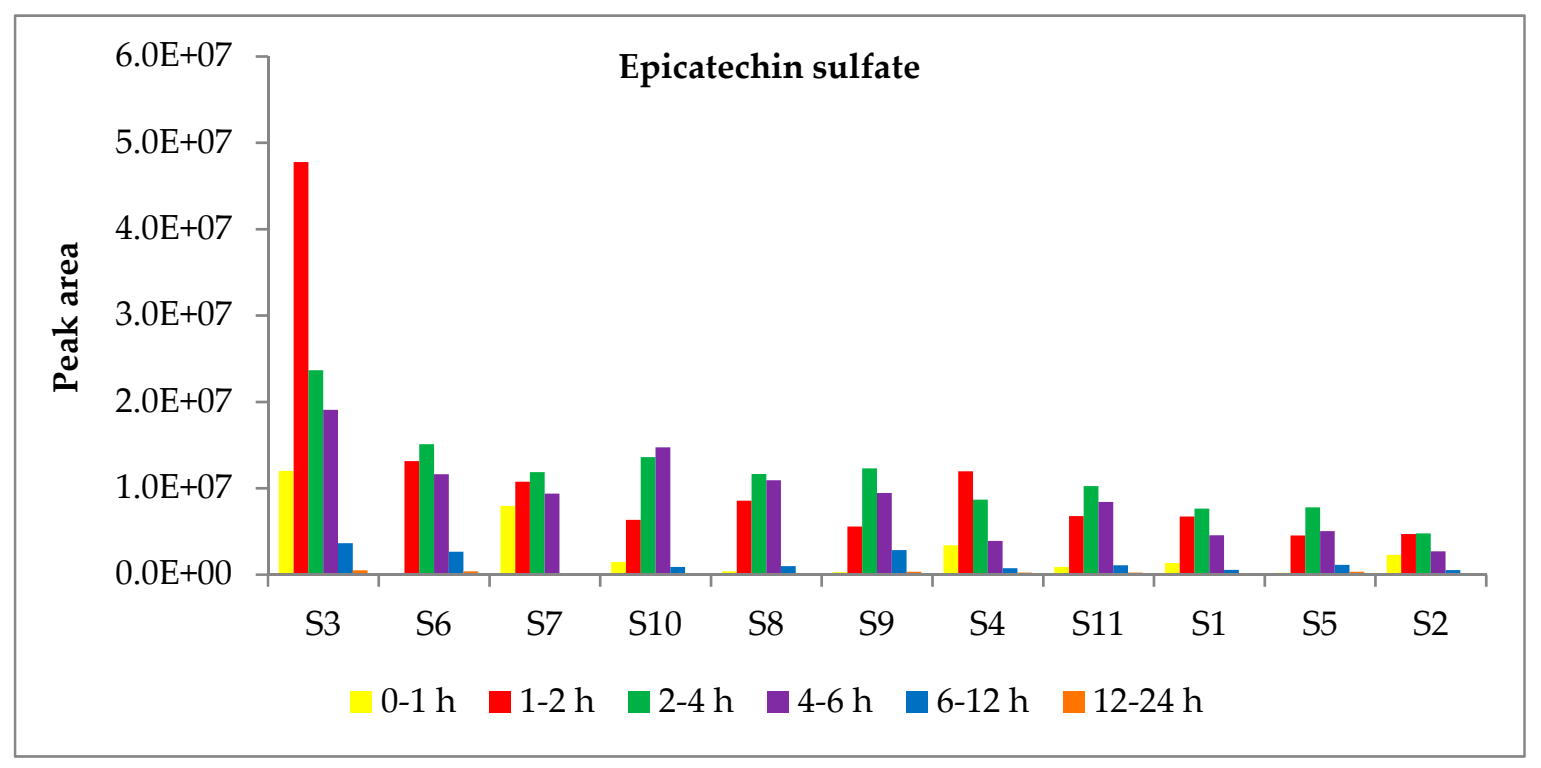

Figure 4. Excretion of epicatechin sulfate in urine in the 11 study participants (S1-11). 0-1 h: yellow bars; 1-2 h: red bars; 2-4 h: green bars; 4-6 h: purple bars; 6-12 h: blue bars; $12-24$ h: orange bars. Subjects were shown in decreasing order according to the AUC in the range T1-T24. 


\section{Discussion}

The biotransformation and bioavailability of monomeric flavan-3-ols has been the subject of many works. These metabolites, particularly (-)-epicatechin, are rapidly absorbed, modified, and released in the bloodstream within 1-4 $\mathrm{h}$ from food consumption and finally excreted in urine in the first 8-12 $\mathrm{h}$ after flavan-3-ol ingestion $[8,22,23,28,45,46]$. Our untargeted analysis demonstrated that (-)-epicatechin phase II metabolites are excreted in urine starting from $1 \mathrm{~h}$ to $6 \mathrm{~h}$ after apple consumption.

PVLs and PVAs are the main circulating metabolites in humans after ingestion of flavan-3-ol -rich food $[5,8,30]$ and their appearance in the bloodstream and excretion in urine is delayed compared to that of monomeric flavan-3-ols, consistent with the microbial formation from flavan-3-ols. PVLs are excreted in amounts up to 10 times higher than (epi)catechin metabolites [22]; nevertheless, they have received less attention and their role is not totally understood yet.

In [32], 15 conjugated PVLs and 8 PVAs were found to be markers of apple juice intake, predominantly sulfate-, glucuronide-, and methoxy conjugates of dihydroxy-PVL and -PVA or combination of thereof (i.e., methoxy-sulfate and methoxy-glucuronide conjugates). Taking into account the flavan-3-ol profile of the apple powder used in this study, the dihydroxy PVLs and PVAs identified could be mainly derivatives of $5-\left(3^{\prime}, 4^{\prime}\right.$-dihydroxyphenyl)- $\gamma$-VL and 4-hydroxy5-( $3^{\prime}, 4^{\prime}$-dihydroxyphenyl)-VA, respectively [8].

The presence of glucuronide- and sulfate-conjugates of PVLs and PVAs have been confirmed in other studies after consumption of almond [6], cocoa [5,23], cranberry [8,35] in human, [36] in murine model, grape [37], and green tea [28,29,38-40].

The most recent literature sheds new light on the health effects connected with flavan-3-ol consumption and these microbial-derived metabolites are emerging as key metabolites [8]. However, there is the need for more data to extend the claims to other flavan-3-ol sources such as apples. In fact, the specific origin and type of flavan-3-ols is important in determining the health effect and safety profile of the bioactive compounds. For example, no adverse effects were reported for the 3-month consumption of $2000 \mathrm{mg} / \mathrm{d}$ of cocoa flavan-3-ols and procyanidins, while the 1-year consumption of $1315 \mathrm{mg}$ of tea flavan-3-ols displayed adverse effects in post-menopausal women [13].

Two factors may influence the time and maximum PVL concentration in human: the degree of flavan-3-ol polymerization and the variation in the metabolic potential between individuals, which results from human genotype and the gut microbiota metabolic pathways.

The type and composition of parent flavan-3-ols determine the type of PVLs that can be biosynthesized; for example, trihydroxy-PVL can be produced only when gallo/epigallocatechin are present in the matrix, as in tea [39], and it is expected that these can be produced after the intake of any food or beverage containing prodelphinidins (such as wine) (see Figure 1 for molecular structures).

The Elstar apples used in this study did not contain notable amounts of gallo/epigallocatechin $(0.004 \mu \mathrm{mol} /$ apple of free epigallocatechin and $0.08 \mu \mathrm{mol} /$ apple of epigallocatechin after phloroglucinolysis; data not shown), and trihydroxy-PVL was not detected. This is expected since apples, similarly to cocoa, only contain procyanidins [20].

The inter-individual variation in the production and excretion of PVLs and PVAs is known to be wide and different factors influence the absorption and metabolism of these compounds, mostly sex, age, dietary habits, and gut microbiota composition [8,39]. The composition of gut microbiota is the most important factor in defining the inter-individual variability in the production of different PVL and PVA aglycones (mono-, di- or trihydroxy-PVL and PVA). In a study by the authors of [42], it was postulated that the production of dihydroxy-PVLs depends on gut microbiota composition rather than the specific food matrix. The presence of bacteria belonging to Clostridia, Actinobacteria, and Propionabacteria genera was positively correlated with this capacity. In a work by the authors of [32], the correlation between PVL and PVA plasma and urinary metabolic profiles with gut microbiota composition revealed that a high production of these metabolites is positively associated with the presence of Dialister, Prevotella, and Escherichia genera and negatively associated with Anaerostipes, Turicibacter, Lachnospiracaea incertae sedis, Coprococcus, and Blautia in faeces. 
Differences in the polymorphism of phase II enzymes also contribute to individual variability in circulating metabolites. In humans, 15 isoforms of UDP-glucuronosyltransferases have been identified and they display wide polymorphic expression patterns, which could explain the high inter-individual variability in glucuronidation of polyphenols $[3,43]$. The sulfonation pathway has higher-affinity than the glucuronidation one but lower capacity, so that when the ingested flavan-3-ol dose increases, a shift from sulfonation toward glucuronidation may occur [44]. This balance is also affected by species, sex, and food deprivation [3].

The existence of metabotypes (also named metabolic phenotypes) has been to date demonstrated for the formation of 8-prenylnaringenin from hop prenylflavonoids [45], equol from soy daidzein [46], urolithins from walnut and pomegranate ellagitannins [47], and PVLs and 3-(hydroxyphenyl)-propionic acid from green tea flavan-3-ols [39]. All these metabolites are microbially formed and the existence of metabotypes can be attributed to differences in the composition of the gut microbiota.

Here, we propose for the first time the presence of different metabotypes with regards to the excretion of dihydroxyPVL phase II conjugates after apple consumption. As our study is conducted with a limited number of subjects, further investigations on a wide number of individuals and repeated time points could shed light on this finding and confirm or reject the hypothesis of the presence of stable metabotypes. Furthermore, detailed information on UDP-glucuronosyltransferase as well as sulfotransferase isoforms involved in the conjugation of dihydroxyPVL is also needed to unravel underlying mechanisms. However, it appears that the variance in the profile of gut microbiota-derived metabolites is higher compared to that of host-derived metabolites, as demonstrated by the fold change differences among subjects (7.9 for PVL and PVA, 2.9 for phase II metabolites of epicatechin).

Conventional wisdom says, "An apple a day keeps the doctor away". However, PVLs and PVAs are likely to be important effectors in determining the beneficial effects of apple consumption. Our results demonstrated that these metabolites, chemically equal to those produced by gut microbiota after ingestion of almond, cocoa, cranberry, red grape and wine, and green tea, are persistent in the human body in consistent amounts up to $24 \mathrm{~h}$ after apple consumption.

It is estimated that the consumption of a single standard serving of apple in Italy ( $150 \mathrm{~g})$ can provide, on average, $101.9 \mathrm{mg}$ of flavan-3-ols [20]. From a bioequivalence view, the consumption of two apples per day could provide the same amount of flavonols as that reported in EFSA NDA panel for cocoa $(200 \mathrm{mg}$ ) [15], therefore, exerting beneficial effects for human health. It is expected that if any of these metabolites are involved in the healthy properties of the apples, the presence of a huge diversity in the capacity to produce these circulating metabolites among subjects should impact the clinical outcome of the study. We suggest that the application of our protocol, providing the intake of a controlled amount of flavan-3-ols followed by the analysis of the 24-h urine, could lead to the selection of groups of participants with similar metabolic capacity, and the subsequent diminution of a major source of variation within clinical studies. The approach could help to define the protective role of dietary flavan-3-ols and their catabolites.

\section{Materials and Methods}

\subsection{Reagents and Chemicals}

Acetonitrile UHPLC-grade and formic acid-MS grade were purchased from Sigma-Aldrich (St. Louis, MO, USA). Ultrapure Milli-Q deionized water was obtained from Elix (Merck-Millipore, Milan, Italy). 5-phenyl- $\gamma$-valerolactone- $3^{\prime}$-sulfate, 5-phenyl- $\gamma$-valerolactone- $3^{\prime}$-glucuronide, 5-(5' hydroxyphenyl)- $\gamma$-valerolactone- $3^{\prime}$-sulfate, 5 -( $3^{\prime}$-hydroxyphenyl)- $\gamma$-valerolactone- $4^{\prime}$-sulfate, and $5-\left(5^{\prime}\right.$ hydroxyphenyl)- $\gamma$-valerolactone- $3^{\prime}$-glucuronide were synthesized in house [31,34]. The nomenclature used follows the rules proposed by [8]. Most of these molecules are catalogued on the standards sharing platform FoodComEx (www.foodcomex.org). 


\subsection{Dietary Intervention and Sample Collection}

This randomized, controlled crossover study was performed at the Division of Human Studies of the Max Rubner-Institut in Karlsruhe, Germany, in January to March 2016, in accordance with the Declaration of Helsinki, approved by the Ethics Committee of the State Medical Chamber Baden-Wuerttemberg (F-2015-101) and registered at the German Clinical Trials Register (DRKS00008787; UTN U-1111-1177-1536). A total of 6 healthy men and 6 women were recruited by advertisements in local media and the MRI study participant data base. Inclusion criteria were age 18-40 years and body mass index (BMI) $18.5-30 \mathrm{~kg} / \mathrm{m}^{2}$. Exclusion criteria were diseases related to digestion, metabolism or excretion of nutrients, known allergies to the intervention food, supplement use within 4 weeks, regular medication except hormonal contraceptives, use of antibiotics within 6 months, pregnancy, lactation, blood donation within 3 months, smoking, and unwillingness to follow dietary restrictions. Eligibility was assessed after taking medical history and physical examination and volunteers provided written informed consent.

Each volunteer was assigned to three different test products in random order: 1) $500 \mathrm{~mL}$ of water as control with $200 \mathrm{~mL}$ of Keto-Drink (TARVALIN AG, Germany) (CT), 2) $400 \mathrm{~g}$ of apples (var. Elstar), cut in slices without apple core) with $200 \mathrm{~mL}$ of Keto-Drink (AP), and 3) $500 \mathrm{~mL}$ of soft drink (Coca Cola ${ }^{\circledR}$ ) with $200 \mathrm{~mL}$ of Keto-Drink (SD) (Figure 5). The Keto-Drink, which was chosen because of its very low sugar content, was purchased from a pharmacy; a detailed composition of the Keto-Drink is given in Table S5; apples and soft drink were from local suppliers. The study arm with the soft drink has no significance for the research question addressed here and was therefore not evaluated in this work.

\begin{tabular}{|c|c|c|c|c|c|c|c|c|c|c|c|c|c|c|c|c|c|c|}
\hline \multirow{5}{*}{ 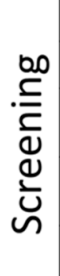 } & \multicolumn{4}{|c|}{ restricted diet } & \multicolumn{3}{|c|}{ normal diet } & \multicolumn{4}{|c|}{ restricted diet } & \multicolumn{3}{|c|}{ normal diet } & \multicolumn{4}{|c|}{ restricted diet } \\
\hline & D-1 & Do & D1 & D2 & D3 & D4 & D5 & D-1 & DO & D1 & $\mathrm{D} 2$ & D3 & D4 & D5 & D-1 & DO & D1 & D2 \\
\hline & \multicolumn{2}{|c|}{ run-in } & \multicolumn{2}{|c|}{ control } & \multicolumn{3}{|c|}{ wash-out } & \multicolumn{2}{|c|}{ run-in } & \multicolumn{2}{|c|}{ apple } & \multicolumn{3}{|c|}{ wash-out } & \multicolumn{2}{|c|}{ run-in } & \multicolumn{2}{|c|}{ coke } \\
\hline & \multicolumn{2}{|c|}{ run-in } & \multicolumn{2}{|c|}{ apple } & \multicolumn{3}{|c|}{ wash-out } & \multicolumn{2}{|c|}{ run-in } & \multicolumn{2}{|c|}{ coke } & \multicolumn{3}{|c|}{ wash-out } & \multicolumn{2}{|c|}{ run-in } & \multicolumn{2}{|c|}{ control } \\
\hline & \multicolumn{2}{|c|}{ run-in } & \multicolumn{2}{|c|}{ coke } & \multicolumn{3}{|c|}{ wash-out } & \multicolumn{2}{|c|}{ run-in } & \multicolumn{2}{|c|}{ control } & \multicolumn{3}{|c|}{ wash-out } & \multicolumn{2}{|c|}{ run-in } & \multicolumn{2}{|c|}{ apple } \\
\hline
\end{tabular}

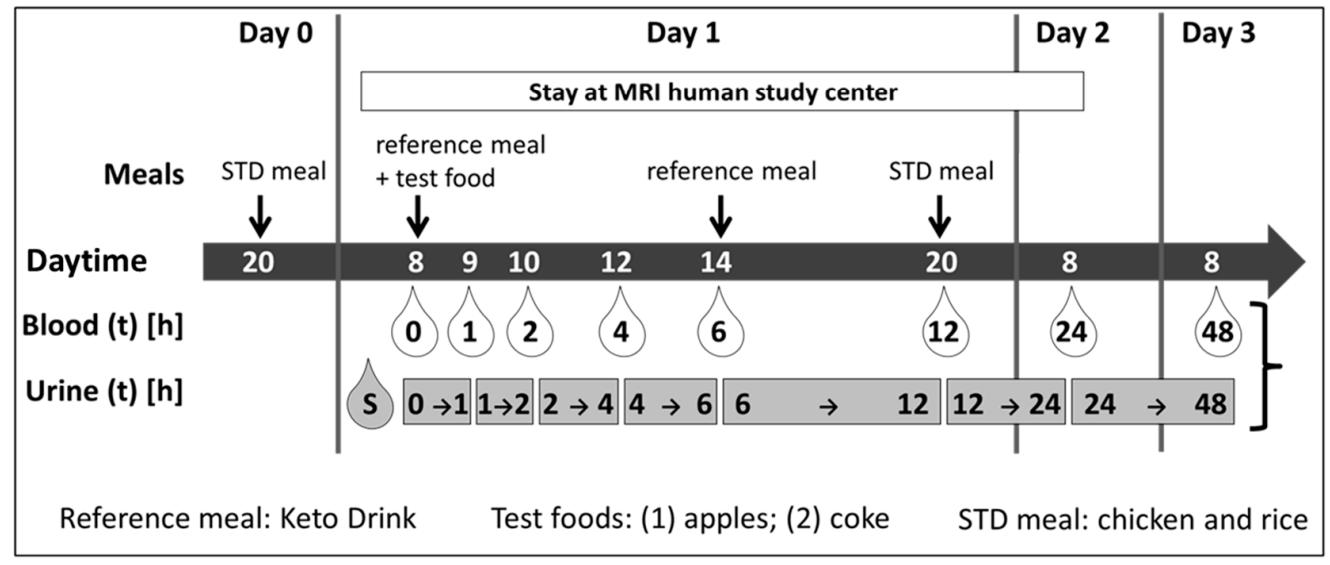

Figure 5. Study design of the randomized, controlled crossover study.

In the morning of the experimental day (Day 2), fasted subjects entered the study center, provided spot urine, and a cannula (Venofix Safety, Braun, Melsungen, Germany) was inserted into an antecubital vein. They stayed overnight until the next morning. Blood was drawn in supine position in S-Monovette tubes (Sarstedt AG, Nümbrecht, Germany) before and 1, 2, 4, 6, 12, and 24 h, respectively, after intake of the test foods. The test foods were consumed within $15 \mathrm{~min}$. Urine samples were concomitantly collected in plastic containers at 0-1 h (T1), 1-2 h (T2), 2-4 h (T4), 4-6 h (T6), 6-12 h (T12), and 12-24 h (T24). Additionally, urine was collected by volunteers at home for the following $24 \mathrm{~h}$ (day 3; 24-48 h), 
stored in provided cooler bags, and immediately brought to the study center. In the evening of Day 1 (run in) and at Day 2 after $12 \mathrm{~h}$, the participants received a standard meal ad libitum (steamed chicken with boiled rice, butter, salt). In addition, at day 2 (6 h), at least $200 \mathrm{~mL}$ of Keto-Drink was provided. The participants were instructed to refrain from fruit and fruit-containing food, as well as sugar-rich beverages and foods during the entire experiment (day 0 to day 3 ). Interventions were separated by a 6-day washout period.

Urine was stored at $4{ }^{\circ} \mathrm{C}$ between collections, and the volume of each interval collection was recorded before preparing aliquots. Urine samples were centrifuged at $1850 \mathrm{~g}\left(4^{\circ} \mathrm{C}, 10 \mathrm{~min}\right)$ to remove cellular particles and debris. Before processing, all urine samples were checked with urine test strips (CombiScreen, CombiScan 100, Analyticon) to exclude samples with pathological aspects and stored at $-80{ }^{\circ} \mathrm{C}$ without preservatives until analysis. Here, we report urinary data from the apple and control intervention part of the study for 6 male and 5 female participants. One female volunteer was excluded from the analysis due to menstrual blood contamination in the urine samples.

\subsection{Sample Preparation for PVL Quantitation}

Urine samples were thawed on ice and vortexed for 10 s. $40 \mu \mathrm{L}$ urine were diluted with $160 \mu \mathrm{L}$ of $0.1 \%$ formic acid in water $(1: 5 ; v / v)$; the samples were centrifuged at $18,000 \times g$ for 5 min and then placed into sealed MS-vial with a $250 \mu \mathrm{L}$ glass insert. Quality control sample was created by pooling $40 \mu \mathrm{L}$ of each sample.

\subsection{Targeted UHPLC-ESI-QqQ-MS}

The method for PVL quantitation was developed and validated by [31]. Briefly, chromatographic separation was performed on a Kinetek EVO C18 $(100 \times 2.1 \mathrm{~mm}$ I.D., $2.6 \mu \mathrm{m}$ particle size $)$ purchased from Phenomenex (Phenomenex, Bologna, Italy). Mobile phase A was water containing $0.2 \%$ formic acid, mobile phase B was acetonitrile with $0.2 \%$ formic acid. The gradient was slightly modified as follows: 5\% B was maintained for $0.5 \mathrm{~min}$, then $25 \% \mathrm{~B}$ was reached in $1.5 \mathrm{~min}$ and maintained for $2 \mathrm{~min}$; then $50 \%$ B was reached in 2 min and finally 95\% B was reached in $1 \mathrm{~min}$ and kept for $1 \mathrm{~min}$. Column was re-equilibrated at starting conditions for $4 \mathrm{~min}$. The flow rate was $0.4 \mathrm{~mL} / \mathrm{min}$, the injection volume was $5 \mu \mathrm{L}$, and the column oven was set at $40^{\circ} \mathrm{C}$. Sample tray temperature was $10^{\circ} \mathrm{C}$.

The detection was performed on a Waters ${ }^{\circledR}$ Xevo QqQ-MS equipped with ESI source (Waters, Milan, Italy). The MS operated in negative ion mode; the capillary was set at $270{ }^{\circ} \mathrm{C}$ and the source at $300{ }^{\circ} \mathrm{C}$; source voltage was $3 \mathrm{kV}$. Ultra-high purity argon was used as collision gas. Characteristic MS conditions were optimized by infusing pure PVLs according to 31. The injection sequence was randomized with regards to study participants and treatments. Quality control samples were acquired at the beginning of the sequence in order to condition the column and stabilize the MS response and were injected every 10 samples in order to address the stability of our measurements.

Calibration curves of standard PVL were prepared by serial dilution and acquired in the range $100 \mu \mathrm{M}-0.1 \mathrm{nM}$. PVAs were quantified by using calibration curves of chemically related PVLs. Results of calibration are reported in Table S1. Data processing was performed using MassLynx V4.1 software (Waters, Milan, Italy).

\subsection{Sample Preparation for Untargeted Analysis and Targeted Selection of Epicatechin Phase II Metabolites}

$100 \mu \mathrm{L}$ of urine were placed into 96-well plate Millipore PVDF and $100 \mu \mathrm{L}$ of internal standards in methanol were added (hyppuric acid-d5 and tryptophan-d5). The mixture was filtered using a positive pressure-96 manifold. Then, $300 \mu \mathrm{L}$ of external standard in MilliQ water (trans-cinnamic acid- $\mathrm{d}_{5}$, cholic acid- $\mathrm{d}_{4}$, octanoyl-L-carnitine- $\mathrm{d}_{3}$ ) were added to the collection plate. Such prepared urine samples were submitted to the LC-LTQ-XL-Orbitrap-MS analysis. Protocol of instrumental analysis was described elsewhere [48]. Data processing protocol was published previously [33]. Briefly, raw data files were converted to mzXML format with the msconvert utility included in ProteoWizard [49]. Profiling data was processed with XCMS [50] using the "matchedFilter" peak picking method. A signal-to-noise ratio 
cut off of 4 was used, full width at half maximum was set to 10s, and a step size of 0.005 Da was used for extracting chromatograms. The resulting feature matrix was annotated using CAMERA [51] to group features corresponding to the same parent ion species. Results from the untargeted experiments will be published in a separate article.

We browsed this dataset and specifically targeted the $m / z$ features of (epi)catechin metabolites according to our previous investigation that was focused on apple intake biomarker discovery [32]: (epi)catechin sulfate ( $m / z$ 369.0279, neg), (epi)catechin glucuronide ( $m / z$ 465.1002, neg), (epi)catechin methoxy sulfate $(\mathrm{m} / \mathrm{z} 383.0416$, neg), and (epi)catechin methoxy glucuronide ( $\mathrm{m} / \mathrm{z} 481.1337$, pos). Mass spectrometry details are reported in Table S6.

\subsection{Determination of Flavan-3-Ols Content in Study Apples}

Elstar apples (approximately $1 \mathrm{~kg}$ ) were cut and cores with seeds were removed. Apples were freeze-dried for 4 days and subsequently ground with a knife mill 3 times for $20 \mathrm{~s}$ each at $8000 \mathrm{rpm}$ (Grindomix GM200; Retsch, Haan, Germany). The powder was stored at $-80{ }^{\circ} \mathrm{C}$ until analysis.

Samples of freeze-dried apples were analysed in triplicate, as described in [20]. $1 \mathrm{~g}$ of powder was diluted with $0.5 \mathrm{~mL}$ of methanol including rosmarinic acid as internal standard (4 ppm). The sample was centrifuged $10 \mathrm{~min}, 15,000 \mathrm{rpm}$ at $4^{\circ} \mathrm{C}$ and the supernatant was filtered with $0.22 \mu \mathrm{m}, 13 \mathrm{~mm}$ Millex-GV PDVF filters (Millipore, Burlington, MA, USA). The phenolic extract was analysed with Waters ${ }^{\circledR}$ UHPLC-ESI-Xevo Triple Quadrupole-MS (Waters ${ }^{\circledR}$, Milford, MA, USA). The content of PACs and their mean degree of polymerization $(\mathrm{mDP})$ was determined by UHPLC-DAD-QqQ-MS before and after phloroglucinolysis, according to validated method protocols [52].

\subsection{Statistical Analyses}

Relative abundance of each metabolite was calculated as percentage respect to each subject cumulative excretion. For low abundant metabolites, zero values were replaced with one-tenth of the minimum value quantifiable with calibration curves. Cluster analysis (complete linkage, Euclidean linkage) was performed with Statistica v 13.3 (TIBCO Software Inc., Palo Alto, CA, USA).

Supplementary Materials: The following are available online at http://www.mdpi.com/2218-1989/9/11/254/s1, Table S1: Flavan-3-ol composition of study apples as determined by UHPLC-ESI-QqQ-MS/DAD; Table S2: Standard compounds used for PVL and PVA quantitation, their retention times, linearity range, curve equation, and R2; Table S3: Quantification of selected PVLs and PVAs at different time points in urine of 11 study subjects; Table S4: Peak intensities of epicatechin phase II metabolites at different time points in urine of 11 study participants; Table S5: Composition of the Keto-Drink; Table S6: Mass spectrometry characteristic of (epi)catechin metabolites in urine samples after apple intake; Figure S1: Cluster analysis based on percentages of excreted epicatechin phase II metabolites in the 11 subjects (complete linkage, Euclidean distance). Metabolomics data have been deposited to the EMBL-EBI MetaboLights database [53] with the identifier MTBLS1313. The complete dataset can be accessed here https://www.ebi.ac.uk/metabolights/MTBLS1313.

Author Contributions: Individual contributions to this manuscript are as follows. Responsible for the study design: F.M. (metabolomics at FEM), S.E.K. and A.B. (FoodBall project at MRI); conceptualization: A.A. (targeted metabolomics), M.U. (untargeted metabolomics); methodology: A.A., P.M., D.D.R., and F.M.; data analysis: A.A.; data interpretation: A.A., S.E.K., A.B., M.U., and F.M.; writing-original draft preparation: A.A. and F.M.; writing-review and editing, final approval: A.A., P.M., S.E.K., A.B., M.U., D.D.R., and F.M.; project administration: S.E.K., A.B., and F.M.; funding acquisition: S.E.K., A.B., and F.M.

Funding: This study was financially supported by the Joint Action Biomarkers in Nutrition and Health, Project Foodball Alliance (FoodBAll) (http://foodmetabolome.org) under the framework of the EU Joint Programming Initiative "A Healthy Diet for a Healthy Life" (JPI HDHL) and the respective national funding organizations, Ministry of Education, University and Research (MIUR), Italy; CUP D43C17000100006 for FEM and German Federal Ministry of Food and Agriculture (BMEL), Grant No. 2814ERA03E for MRI.

Acknowledgments: We are thankful to Daniele Perenzoni (Edmund Mach Foundation) for determination of flavan-3-ol content in the apple study, to Claudio Curti (University of Parma) for providing the standards of PVLs, and to Christoph $\mathrm{H}$. Weinert for providing data on Elstar apples.

Conflicts of Interest: The authors declare no conflict of interest. The funders had no role in the design of the study; in the collection, analyses, or interpretation of data; in the writing of manuscript, or in the decision to publish the results. 


\section{References}

1. Solicitation of Written Comments on Proposed Definition of Bioactive Food Component. Available online: https://www.govinfo.gov/content/pkg/FR-2004-09-16/pdf/04-20892.pdf (accessed on 14 October 2019).

2. Hollman, P.C.; Arts, I.C.; Hollman, P.C.H.; Arts, I.C.W. Flavonols, flavones and flavanols-Nature, occurrence and dietary burden. J. Sci. Food Agric. 2000, 80, 1081-1093. [CrossRef]

3. Manach, C.; Scalbert, A.; Morand, C.; Rémésy, C.; Jiménez, L. Polyphenols: Food sources and bioavailability. Am. J. Clin. Nutr. 2004, 79, 727-747. [CrossRef] [PubMed]

4. Serra, A.; Macià, A.; Romero, M.-P.; Salvadó, M.-J.; Bustos, M.; Fernández-Larrea, J.; Motilva, M.-J. Determination of procyanidins and their metabolites in plasma samples by improved liquid chromatography-tandem mass spectrometry. J. Chromatogr. 2009, 877, 1169-1176. [CrossRef] [PubMed]

5. Urpi-Sarda, M.; Monagas, M.; Khan, N.; Llorach, R.; Raventós, R.M.; Jáuregui, O.; Estruch, R.; Izquierdo-Pulido, M.; Andres-Lacueva, C. Targeted metabolic profiling of phenolics in urine and plasma after regular consumption of cocoa by liquid chromatography-tandem mass spectrometry. J. Chromatogr. 2009, 1216, 7258-7267. [CrossRef]

6. Urpi-Sarda, M.; Garrido, I.; Monagas, M.; Gòmez-Cordovés, C.; Medina-Remòn, A.; Andrès-Lacueva, C.; Bartolomé, B. Profile of Plasma and Urine Metabolites after the Intake of Almond [Prunus dulcis (Mill.) D.A. Webb] Polyphenols in Humans. J. Agric. Food Chem. 2009, 57, 10134-10142. [CrossRef]

7. Del Rio, D.; Rodriguez-Mateos, A.; Spencer, J.P.E.; Tognolini, M.; Borges, G.; Crozier, A. Dietary (poly)phenolics in human health: Structures, bioavailability, and evidence of protective effects against chronic diseases. Antioxid. Redox Signal. 2013, 18, 1818-1892. [CrossRef]

8. Mena, P.; Bresciani, L.; Brindani, N.; Ludwig, I.A.; Pereira-Caro, G.; Angelino, D.; Llorach, R.; Calani, L.; Brighenti, F.; Clifford, M.N.; et al. Phenyl- $\gamma$-valerolactones and phenylvaleric acids, the main colonic metabolites of flavan-3-ols: Synthesis, analysis, bioavailability, and bioactivity. Nat. Prod. Rep. 2019, 36, 714-752. [CrossRef]

9. Hooper, L.; Kay, C.; Abdelhamid, A.; A Kroon, P.; Cohn, J.S.; Rimm, E.B.; Cassidy, A. Effects of chocolate, cocoa, and flavan-3-ols on cardiovascular health: A systematic review and meta-analysis of randomized trials. Am. J. Clin. Nutr. 2012, 95, 740-751. [CrossRef]

10. Sansone, R.; Rodriguez-Mateos, A.; Heuel, J.; Falk, D.; Schuler, D.; Wagstaff, R.; Kuhnle, G.G.C.; Spencer, J.P.E.; Schroeter, H.; Merx, M.W.; et al. Cocoa flavanol intake improves endothelial function and Framingham Risk Score in healthy men and women: A randomised, controlled, double-masked trial: The Flaviola Health Study. Br. J. Nutr. 2015, 114, 1246-1255. [CrossRef]

11. Ludovici, V.; Barthelmes, J.; Nägele, M.P.; Enseleit, F.; Ferri, C.; Flammer, A.J.; Ruschitzka, F.; Sudano, I. Cocoa, Blood Pressure, and Vascular Function. Front. Nutr. 2017, 4, 36. [CrossRef]

12. González-Sarrías, A.; Combet, E.; Pinto, P.; Mena, P.; Dall'Asta, M.; Aloy, M.G.; Rodriguez-Mateos, A.; Gibney, E.R.; Dumont, J.; Massaro, M.; et al. A systematic review and meta-analysis of the effects of flavanol-containing tea, cocoa and apple products on body composition and blood lipids: Exploring the factors responsible for variability in their efficacy. Nutrients 2017, 9, 746. [CrossRef]

13. Ottaviani, J.I.; Heiss, C.; Spencer, J.P.; Kelm, M.; Schroeter, H. Recommending flavanols and procyanidins for cardiovascular health: Revisited. Mol. Asp. Med. 2018, 61, 63-75. [CrossRef] [PubMed]

14. Magrone, T.; Russo, M.A.; Jirillo, E. Cocoa and Dark Chocolate Polyphenols: From Biology to Clinical Applications. Front. Immunol. 2017, 8, 677. [CrossRef] [PubMed]

15. Scientific Opinion on the Modification of the Authorisation of a Health Claim Related to Cocoa Flavanols and Maintenance of Normal Endothelium-Dependent Vasodilation Pursuant to Article 13(5) of Regulation (EC) No 1924/2006 Following a Request in Accordan. EFSA J. 2014, 12. Available online: https://efsa.onlinelibrary. wiley.com/doi/epdf/10.2903/j.efsa.2014.3654 (accessed on 14 October 2019).

16. Boyer, J.; Liu, R.H. Apple phytochemicals and their health benefits. Nutr. J. 2004, 3, 5. [CrossRef]

17. Bondonno, C.P.; Yang, X.; Croft, K.D.; Considine, M.J.; Ward, N.C.; Rich, L.; Puddey, I.B.; Swinny, E.; Mubarak, A.; Hodgson, J.M. Flavonoid-rich apples and nitrate-rich spinach augment nitric oxide status and improve endothelial function in healthy men and women: A randomized controlled trial. Free. Radic. Biol. Med. 2012, 52, 95-102. [CrossRef] 
18. Bondonno, N.P.; Bondonno, C.P.; Blekkenhorst, L.C.; Considine, M.J.; Maghzal, G.; Stocker, R.; Woodmann, R.J.; Ward, N.C.; Hodgson, J.M.; Croft, K.D. Flavonoid-Rich Apple Improves Endothelial Function in Individuals at Risk for Cardiovascular Disease: A Randomized Controlled Clinical Trial. Mol. Nutr. Food Res. 2018, 62, 3. [CrossRef]

19. Schroeter, H.; Heiss, C.; Balzer, J.; Kleinbongard, P.; Keen, C.L.; Hollenberg, N.K.; Sies, H.; Kwik-Uribe, C.; Schmitz, H.H.; Kelm, M. (-)-Epicatechin mediates beneficial effects of flavanol-rich cocoa on vascular function in humans. Proc. Natl. Acad. Sci. USA 2006, 103, 1024-1029. [CrossRef]

20. Vrhovsek, U.; Rigo, A.; Tonon, D.; Mattivi, F. Quantitation of Polyphenols in Different Apple Varieties. J. Agric. Food Chem. 2004, 52, 6532-6538. [CrossRef]

21. Farneti, B.; Masuero, D.; Costa, F.; Magnago, P.; Malnoy, M.; Costa, G.; Vrhovsek, U.; Mattivi, F. Is There Room for Improving the Nutraceutical Composition of Apple? J. Agric. Food Chem. 2015, 63, 2750-2759. [CrossRef]

22. Del Rio, D.; Calani, L.; Cordero, C.E.I.; Salvatore, S.; Pellegrini, N.; Brighenti, F. Bioavailability and catabolism of green tea flavan-3-ols in humans. Nutrition 2010, 26, 1110-1116. [CrossRef] [PubMed]

23. Rodríguez-Mateos, A.; Cifuentes-Gomez, T.; Gonzalez-Salvador, I.; Ottaviani, J.I.; Schroeter, H.; Kelm, M.; Heiss, C.; Spencer, J.P.E.; Rodriguez-Mateos, A.; Cifuentes-Gomez, T.; et al. Influence of age on the absorption, metabolism, and excretion of cocoa flavanols in healthy subjects. Mol. Nutr. Food Res. 2015, 59, 1504-1512. [CrossRef] [PubMed]

24. Wiese, S.; Esatbeyoglu, T.; Winterhalter, P.; Kruse, H.-P.; Winkler, S.; Bub, A.; Kulling, S.E. Comparative biokinetics and metabolism of pure monomeric, dimeric, and polymeric flavan-3-ols: A randomized cross-over study in humans. Mol. Nutr. Food Res. 2015, 59, 610-621. [CrossRef] [PubMed]

25. Monagas, M.; Urpi-Sarda, M.; Sánchez-Patán, F.; Llorach, R.; Garrido, I.; Gómez-Cordovés, C.; Andres-Lacueva, C.; Bartolomé, B. Insights into the metabolism and microbial biotransformation of dietary flavan-3-ols and the bioactivity of their metabolites. Food Funct. 2010, 1, 233. [CrossRef] [PubMed]

26. Ottaviani, J.I.; Fong, R.; Kimball, J.; Ensunsa, J.L.; Britten, A.; Lucarelli, D.; Luben, R.; Grace, P.B.; Mawson, D.H.; Tym, A.; et al. Evaluation at scale of microbiome-derived metabolites as biomarker of flavan-3-ol intake in epidemiological studies. Sci. Rep. 2018, 8, 9859. [CrossRef]

27. Ottaviani, J.I.; Kwik-Uribe, C.; Keen, C.L.; Schroeter, H. Intake of dietary procyanidins does not contribute to the pool of circulating flavanols in humans. Am. J. Clin. Nutr. 2012, 95, 851-858. [CrossRef]

28. Stalmach, A.; Mullen, W.; Steiling, H.; Williamson, G.; Lean, M.E.J.; Crozier, A. Absorption, metabolism, and excretion of green tea flavan-3-ols in humans with an ileostomy. Mol. Nutr. Food Res. 2010, 54, 323-334. [CrossRef]

29. Van Der Hooft, J.J.J.; De Vos, R.C.H.; Mihaleva, V.; Bino, R.J.; Ridder, L.; De Roo, N.; Jacobs, D.M.; Van Duynhoven, J.P.M.; Vervoort, J. Structural Elucidation and Quantification of Phenolic Conjugates Present in Human Urine after Tea Intake. Anal. Chem. 2012, 84, 7263-7271. [CrossRef]

30. Ottaviani, J.I.; Borges, G.; Momma, T.Y.; Spencer, J.P.E.; Keen, C.L.; Crozier, A.; Schroeter, H. The metabolome of [2-14C] (-)-epicatechin in humans: Implications for the assessment of efficacy, safety and mechanisms of action of polyphenolic bioactives. Sci. Rep. 2016, 6, 29034. [CrossRef]

31. Brindani, N.; Mena, P.; Calani, L.; Benzie, I.; Choi, S.-W.; Brighenti, F.; Zanardi, F.; Curti, C.; Del Rio, D.; Choi, S. Synthetic and analytical strategies for the quantification of phenyl- $\gamma$-valerolactone conjugated metabolites in human urine. Mol. Nutr. Food Res. 2017, 61, 1700077. [CrossRef]

32. Trôst, K.; Ulaszewska, M.M.; Stanstrup, J.; Albanese, D.; De Filippo, C.; Tuohy, K.M.; Natella, F.; Scaccini, C.; Mattivi, F. Host: Microbiome co-metabolic processing of dietary polyphenols - An acute, single blinded, cross-over study with different doses of apple polyphenols in healthy subjects. Food Res. Int. 2018, 112, 108-128. [CrossRef] [PubMed]

33. Ulaszewska, M.M.; Trost, K.; Stanstrup, J.; Tuohy, K.M.; Franceschi, P.; Chong, M.F.-F.; George, T.; Minihane, A.M.; Lovegrove, J.A.; Mattivi, F. Urinary metabolomic profiling to identify biomarkers of a flavonoid-rich and flavonoid-poor fruits and vegetables diet in adults: The FLAVURS trial. Metabolomics 2016, 12, 32. [CrossRef]

34. Curti, C.; Brindani, N.; Battistini, L.; Sartori, A.; Pelosi, G.; Mena, P.; Brighenti, F.; Zanardi, F.; Del Rio, D. Catalytic, Enantioselective Vinylogous Mukaiyama Aldol Reaction of Furan-Based Dienoxy Silanes: A Chemodivergent Approach to $\gamma$-Valerolactone Flavan-3-ol Metabolites and $\delta$-Lactone Analogues. Adv. Synth. Catal. 2015, 357, 4082-4092. [CrossRef] 
35. Rodriguez-Mateos, A.; Feliciano, R.P.; Boeres, A.; Weber, T.; Dos Santos, C.N.; Ventura, M.R.; Heiss, C.; Rodriguez-Mateos, A. Cranberry (poly)phenol metabolites correlate with improvements in vascular function: A double-blind, randomized, controlled, dose-response, crossover study. Mol. Nutr. Food Res. 2016, 60, 2130-2140. [CrossRef] [PubMed]

36. Vauzour, D.; Rodriguez-Ramiro, I.; Rushbrook, S.; Ipharraguerre, I.R.; Bevan, D.; Davies, S.; Tejera, N.; Mena, P.; De Pascual-Teresa, S.; Del Rio, D.; et al. n-3 Fatty acids combined with flavan-3-ols prevent steatosis and liver injury in a murine model of NAFLD. Biochim. Biophys. Acta Mol. Basis Dis. 2018, 1864, 69-78. [CrossRef] [PubMed]

37. Castello, F.; Costabile, G.; Bresciani, L.; Tassotti, M.; Naviglio, D.; Luongo, D.; Ciciola, P.; Vitale, M.; Vetrani, C.; Galaverna, G.; et al. Bioavailability and pharmacokinetic profile of grape pomace phenolic compounds in humans. Arch. Biochem. Biophys. 2018, 646, 1-9. [CrossRef] [PubMed]

38. Van Duynhoven, J.; Van Der Hooft, J.J.J.; Van Dorsten, F.A.; Peters, S.; Foltz, M.; Gomez-Roldan, V.; Vervoort, J.; De Vos, R.C.H.; Jacobs, D.M. Rapid and Sustained Systemic Circulation of Conjugated Gut Microbial Catabolites after Single-Dose Black Tea Extract Consumption. J. Proteome Res. 2014, 13, 2668-2678. [CrossRef]

39. Mena, P.; Ludwig, I.A.; Tomatis, V.B.; Acharjee, A.; Calani, L.; Rosi, A.; Brighenti, F.; Ray, S.; Griffin, J.L.; Bluck, L.J.; et al. Inter-individual variability in the production of flavan-3-ol colonic metabolites: Preliminary elucidation of urinary metabotypes. Eur. J. Nutr. 2019, 58, 1529-1543. [CrossRef]

40. Li, C.; Lee, M.-J.; Sheng, S.; Meng, X.; Prabhu, S.; Winnik, B.; Huang, B.; Chung, J.Y.; Yan, S.; Ho, C.-T.; et al. Structural Identification of Two Metabolites of Catechins and Their Kinetics in Human Urine and Blood after Tea Ingestion. Chem. Res. Toxicol. 2000, 13, 177-184. [CrossRef]

41. Lee, M.-J.; Maliakal, P.; Chen, L.; Meng, X.; Bondoc, F.Y.; Prabhu, S.; Lambert, G.; Mohr, S.; Yang, C.S. Pharmacokinetics of tea catechins after ingestion of green tea and (-)-epigallocatechin-3-gallate by humans: Formation of different metabolites and individual variability. Cancer Epidemiol. Biomark. Prev. 2002, 11, 1025-1032.

42. Van Velzen, E.J.J.; Westerhuis, J.A.; Grün, C.H.; Jacobs, D.M.; Eilers, P.H.C.; Mulder, T.P.; Foltz, M.; Garczarek, U.; Kemperman, R.; Vaughan, E.E.; et al. Population-based nutrikinetic modeling of polyphenol exposure. Metabolomics 2014, 10, 1059-1073. [CrossRef]

43. Miners, J.O.; A McKinnon, R.; I MacKenzie, P. Genetic polymorphisms of UDP-glucuronosyltransferases and their functional significance. Toxicology 2002, 181, 453-456. [CrossRef]

44. Koster, H.; Halsema, I.; Scholtens, E.; Knippers, M.; Mulder, G.J. Dose-dependent shifts in the sulfation and glucuronidation of phenolic compounds in the rat in vivo and in isolated hepatocytes. Biochem. Pharmacol. 1981, 30, 2569-2575. [CrossRef]

45. Bolca, S.; Possemiers, S.; Maervoet, V.; Huybrechts, I.; Heyerick, A.; Vervarcke, S.; Depypere, H.; De Keukeleire, D.; Bracke, M.; De Henauw, S.; et al. Microbial and dietary factors associated with the 8-prenylnaringenin producer phenotype: A dietary intervention trial with fifty healthy post-menopausal Caucasian women. Br. J. Nutr. 2007, 98, 950-959. [CrossRef] [PubMed]

46. Setchell, K.D.R.; Brown, N.M.; Summer, S.; King, E.C.; Heubi, J.E.; Cole, S.; Guy, T.; Hokin, B. Dietary factors influence production of the soy isoflavone metabolite s-(-)equol in healthy adults. J. Nutr. 2013, 143, 1950-1958. [CrossRef]

47. Tomás-Barberán, F.A.; García-Villalba, R.; González-Sarrías, A.; Selma, M.V.; Espín, J.C. Ellagic Acid Metabolism by Human Gut Microbiota: Consistent Observation of Three Urolithin Phenotypes in Intervention Trials, Independent of Food Source, Age, and Health Status. J. Agric. Food Chem. 2014, 62, 6535-6538. [CrossRef]

48. Ancillotti, C.; Ulaszewska, M.; Mattivi, F.; Del Bubba, M. Untargeted Metabolomics Analytical Strategy Based on Liquid Chromatography/Electrospray Ionization Linear Ion Trap Quadrupole/Orbitrap Mass Spectrometry for Discovering New Polyphenol Metabolites in Human Biofluids after Acute Ingestion of Vaccinium myrti. J. Am. Soc. Mass Spectrom. 2019, 30, 381-402. [CrossRef]

49. Chambers, M.C.; MacLean, B.; Burke, R.; Amodei, D.; Ruderman, D.L.; Neumann, S.; Gatto, L.; Fischer, B.; Pratt, B.; Egertson, J.; et al. A cross-platform toolkit for mass spectrometry and proteomics. Nat. Biotechnol. 2012, 30, 918-920. [CrossRef] 
50. Smith, C.A.; Want, E.J.; O'Maille, G.; Abagyan, R.; Siuzdak, G. XCMS: Processing Mass Spectrometry Data for Metabolite Profiling Using Nonlinear Peak Alignment, Matching, and Identification. Anal. Chem. 2006, 78, 779-787. [CrossRef]

51. Kuhl, C.; Tautenhahn, R.; Böttcher, C.; Larson, T.R.; Neumann, S. CAMERA: An Integrated Strategy for Compound Spectra Extraction and Annotation of Liquid Chromatography/Mass Spectrometry Data Sets. Anal. Chem. 2012, 84, 283-289. [CrossRef]

52. Gris, E.F.; Mattivi, F.; Ferreira, E.A.; Vrhovsek, U.; Pedrosa, R.C.; Bordignon-Luiz, M.T. Proanthocyanidin profile and antioxidant capacity of Brazilian Vitis vinifera red wines. Food Chem. 2011, 126, 213-220. [CrossRef]

53. Haug, K.; Salek, R.M.; Conesa, P.; Hastings, J.; de Matos, P.; Rijnbeek, M.; Mahendraker, T.; Williams, M.; Neumann, S.; Rocca-Serra, P.; et al. MetaboLights-An open-access general-purpose repository for metabolomics studies and associated meta-data. Nucleic Acids Res. 2013, 41, D781-D786. [CrossRef] [PubMed]

(C) 2019 by the authors. Licensee MDPI, Basel, Switzerland. This article is an open access article distributed under the terms and conditions of the Creative Commons Attribution (CC BY) license (http://creativecommons.org/licenses/by/4.0/). 